2015-05

\title{
Coital incontinence: what can we learn from urodynamic assessment?
}

Madhu, K

http://hdl.handle.net/10026.1/4400

10.1016/j.urology.2015.02.007

Urology

All content in PEARL is protected by copyright law. Author manuscripts are made available in accordance with publisher policies. Please cite only the published version using the details provided on the item record or document. In the absence of an open licence (e.g. Creative Commons), permissions for further reuse of content should be sought from the publisher or author. 


\title{
Coital Incontinence and lower urinary tract symptoms: is there an
} association?

\author{
Accepted on 09/02/2015 at Urology
}

Abstract

\section{Introduction}

Involuntary loss of urine with intercourse, or coital incontinence (CI), can be highly bothersome. The pathophysiology of CI is unclear. This study aimed to assess and understand the association of CI with lower urinary tract symptom (LUTS).

\section{Methods}

A database of all women who underwent urodynamic testing in a tertiary referral centre in the UK, from Jan 1991 to Dec 2009 was retrospectively analyzed. All women reporting CI were included in the study. Urodynamic testing and interpretation of results were done in accordance with the recommendations of the International Continence Society.

\section{Results}

The prevalence of CI in women undergoing urodynamics was $11.8 \%$ and they were significantly younger than the control group. Obesity (BMI>30) (32.5\%) and parity $($ mean $=2.5)$ were significantly associated with $\mathrm{CI}(\mathrm{p}<0.001)$. Women reporting CI significantly smoked cigarettes $(26.8 \%, \mathrm{p}<0.001)$ and used antidepressants $(12.4 \%, \mathrm{p}<0.001)$. Compared to the control group, there were fewer post-menopausal women with CI. Previous hysterectomy had a negative association with $\mathrm{CI}(\mathrm{OR}=0.8)$. The majority of women had overactive bladder (OAB) symptoms $(65 \%)$ and stress urinary incontinence $(94.8 \%)(\mathrm{p}<0.001)$. Both urodynamic stress incontinence (UDSI) and detrusor overactivity (DO) were significantly associated with CI $(\mathrm{p}<0.001)$. Detrusor overactivity incontinence (DOI) had a negative correlation (OR=0.65. $\mathrm{p}<0.001)$.

\section{Conclusion}

CI is not uncommon in women with LUTS and they present earlier than women with LUTS and no CI. CI is significantly associated with risk factors like parity, obesity, cigarette smoking and anti-depressant usage. Coital incontinence is multifactorial and associated with UDSI and DO, but not DOI. 


\section{Introduction}

Coital incontinence is a complaint of involuntary loss of urine with coitus or sexual intercourse and can be divided further into that occurring with penetration or that occurring with orgasm (1). It is reported to occur in up to $60 \%$ of sexually active women and is a manifestation of an underlying pelvic floor dysfunction (2). Varied mechanisms including stress incontinence, detrusor overactivity and prolapse have been proposed $(3,4)$. However, coital incontinence can be a challenging condition to manage ${ }_{2}$ as the exact mechanisms of its etiology still remains unclear (2). It is an under-reported problem and may not be readily discussed due to patient embarrassment (5). This makes it difficult to understand and research. Coital incontinence also has a negative impact on a woman's quality of life and sexuality (6). All these factors make it an important condition to understand as it might have an impact on the outcomes of managing other lower urinary tract symptoms (LUTS).

The aim of this study was to evaluate and understand the functional abnormalities associated with coital incontinence. This study is a review of a large database of women undergoing urodynamics for various lower urinary tract symptoms, including coital incontinence.

\section{Methods:}

The study was conducted in a tertiary referral centre performing about 1000 urodynamic studies a year, in men and women. All women undergoing urodynamic testing over a 20-year period from Jan 1991 to Dec 2009 were included in the study. Women were referred with various LUTS for urodynamic investigations. Ethical approval was obtained from the regional ethical committee prior to conducting this study.

A detailed history including demographic details was taken prior to urodynamic testing including LUTS and coital incontinence. All the details were entered on to a specific urodynamic database. Women then underwent urodynamic testing in accordance with the recommendations of the ICS (7). All women underwent 
uroflowmetry, filling cystometry and pressure flow studies. Urine dipstick was routinely done to rule out infection and women with infections were treated and rebooked for urodynamic testing. Women on antimuscarinics were also advised to stop the medication for at least a week prior to the test. Urodynamic findings and diagnosis were defined based on the International Continence Society recommendations (8). Women who reported coital incontinence were included in the study group and compared to women who did not have coital incontinence. Women without coital incontinence were the control group. No distinction was made between incontinence on penetration or orgasm. Women were filled in the upright position, starting at $50 \mathrm{ml} / \mathrm{min}$ using normal saline at room temperature.

Data from the urodynamic database was anonymized and cleaned for clarity, and then analyzed using SPSS (IBM SPSS Statistics for Windows, Version 21.0. Armonk, NY: IBM Corp). Student's t-test was used for testing differences in the mean between two continuous variables, while a Chi-square test was used for testing associations between categorical variables. Unless specified otherwise, all tests were made at a 5\% level of significance. Whenever appropriate, p-values and $95 \%$ confidence intervals were computed and included in the result.

\section{Results:}

Data from 11,689 women who underwent urodynamic testing for various LUTS during the study period from Jan 1991 to Dec 2009 were suitable for analysis. 1,391 women with LUTS reported coital incontinence with a prevalence rate of coital incontinence of $11.8 \%$. The demographic details of women in the study are summarized in table 1 . The mean age of women reporting coital incontinence in the study group was 45.3 years, which was significantly lower than women in the control group (52.4 years, $\mathrm{p}<0.001$ ). High BMI was also significantly associated with coital incontinence and was seen in $24.3 \%$ cases $(\mathrm{OR}=1.4, \mathrm{p}<0.001)$. $\underline{\mathrm{A}}$ significant proportion of women with CI (23.6\%) reported cigarette smoking $(\mathrm{OR}=1.4, \mathrm{P}<0.001) .12 .5 \%$ women also reported using antidepressant medications, which was statistically significant $(\mathrm{OR}=1.4, \mathrm{P}<0.001)$. The mean 
parity in women with coital incontinence was 2.5, which was higher than in the control group $(2.3, \mathrm{p}<0.001) .28 .2 \%$ of women in the coital incontinence group had had a previous hysterectomy and this had a negative association with coital incontinence $(\mathrm{OR}=0.8, \mathrm{p}<0.001)$.

Important LUTS and urodynamic findings in the study are summarized in table 2. There was no statistically important difference noted in the mean daytime frequency. However, women with coital incontinence had significantly lesser mean nocturia episodes (1.1 V 1.2, p<0.001). 65\% of women with coital incontinence complained of overactive bladder symptoms $(\mathrm{OR}=1.17, \mathrm{p}<0.001)$ and $95 \%$ complained of stress incontinence $(\mathrm{OR}=3.9, \mathrm{p}<0.001)$. Women with coital incontinence were less likely to have normal urodynamic findings (OR= 0.63, $\mathrm{p}<0.001)$. Urodynamic stress incontinence was the most significant urodynamic finding demonstrable in the study and was seen in $68 \%$ of women with coital incontinence $(\mathrm{OR}=2.4, \mathrm{p}<0.001)$. Detrusor overactivity was also significantly associated with coital incontinence and was seen in $47 \%$ cases (OR= $1.2, \mathrm{p}<0.001$ ). Detrusor overactivity incontinence (DOI) was seen in $9.6 \%$ cases in the study group compared to $14.1 \%$ in the control group (OR=0.65, $\mathrm{p}<0.001)$. A combination of urodynamic stress incontinence with DOI did not reach statistical significance $(\mathrm{OR}=1.1, \mathrm{p}=0.155))$.

\section{Discussion}

This study reports risk factors, LUTS and urodynamics findings in women with coital incontinence from a large database. Women with coital incontinence were significantly younger and presented earlier. Higher parity, obesity, cigarette smoking and antidepressant usage were significant risk factors associated with coital incontinence. Most women with coital incontinence presented with mixed storage urinary symptoms (SUI+ OAB). Women with coital incontinence were less likely to have normal urodynamic findings. Urodynamic stress incontinence and detrusor overactivity were both significantly associated with coital incontinence. The database (study) did not differentiate between coital incontinence on penetration and/or with orgasm, which is a limitation of the study. Women were also not followed up to evaluate the outcomes of their 
management to correlate their LUTS and urodynamic findings with coital incontinence.

Prevalence of coital incontinence in women presenting with LUTS in the study was $11.8 \%$. There is a wide variation in the literature in the reported prevalence of coital incontinence ranging from 10 to $60 \%$ of sexually active women with pelvic floor pathologies $(2,5,9,10)$. These studies vary in their setting and methodology. Coital incontinence is routinely enquired at history taking in our centre and all the details were contemporaneously entered onto a database. Coital incontinence, however may not generally be readily discussed due to patient or physician embarrassment, which will affect reporting and research $(5,9)$. Coital incontinence affects patient quality of life and sexuality ${ }_{2}$ and women with coital incontinence report worse quality of life scores (6). It also has an effect on sexual function outcomes of management of urinary incontinence (11). These factors make it highly relevant to enquire about coital incontinence in women with LUTS. The prevalence rate in this study could be an underestimation as patients might not have revealed it at history taking and use of methods avoiding face-to-face consultation, such as questionnaires, might have shown a higher rate (2). This prevalence rate is also in women who presented with LUTS including incontinence. The 'true' prevalence rate of coital incontinence in women with or without LUTS will need further epidemiological studies.

There was a slightly lesser mean nocturia episode in women with coital incontinence. This small difference is very unlikely to be of clinical significance particularly as nocturia severity was lower than the threshold of at least 2 episodes of nocturia generally thought to affect health related quality of life (12). High BMI was significantly associated with coital incontinence. Epidemiological studies have shown an increased association of high BMI with urinary incontinence (13). Obesity is associated with a chronic state of increased abdominal pressure, which might stress the pelvic floor (14). Intercourse puts further stress on pelvic floor and also increases the intra-abdominal pressure, resulting in coital incontinence. Women with coital incontinence also had a 
slightly increased mean parity in the study, which was statistically significant. Parity is known to be a risk factor for urinary incontinence (15). Parity can be used as an indicator of the combined effects of pregnancy and childbirth on the pelvic floor and its contribution to pelvic floor pathologies.

The women with coital incontinence were significantly younger than the control group possibly suggesting an earlier presentation. Coital incontinence, is known to have a negative impact on a woman's quality of life and sexuality (6), which may have an effect on a woman's health seeking behavior. Hence, women with CI might seek health care advice early. This may also have an effect on patient expectations and outcomes of management.

Cigarette smoking was significantly higher in women with coital incontinence. Smoking is known to be associated with both stress urinary incontinence and detrusor overactivity $(16,17)$. Excessive and violent coughing in smokers, even in the presence of high urethral closure pressures, predisposes to stress urinary incontinence (18), but this logically doesn't suggest it as a mechanism of incontinence with sexual intercourse. Cigarette smoking has anti-estrogenic effects and it also affects collagen synthesis (16), which might explain a higher association with coital incontinence.

Antidepressants were also significantly associated with coital incontinence in our study. The association could be causal or it might suggest an increased antidepressant use in women with coital incontinence due to low mood. Urinary incontinence is known to be associated with anxiety, depression and lower quality of life (19). Coital incontinence in addition to other LUTS also affects a woman's sexuality (6). These factors may contribute to an increase use of antidepressants in women with coital incontinence. Antidepressants may also influence central or local neurological control of bladder function and may cause urinary incontinence $(20,21)$. Serotonin may have a regulatory role in bladder functioning (22). Altered serotoninergic pathways could also explain a direct correlation with depression and urinary incontinence or with use of antidepressant use (23). 
There were fewer menopausal women reporting CI and a younger cohort of women in the study group could explain this. Estrogen affects the lower urinary tract and menopause is associated with urinary incontinence $(24,25)$. The lower number of menopausal women in the study group suggests a different mechanism of $\mathrm{CI}$, which might not be estrogen dependent. It is also plausible that there were fewer sexually active women in the older group (data not available from the database). There is a higher risk of urinary incontinence in older women with hysterectomy $(26,27)$. Fewer women with a previous hysterectomy and a younger cohort of patients in the study group might explain the negative correlation of a previous hysterectomy with coital incontinence. There is an increasing trend of hysterectomy with increasing age (28); the younger mean age of the women in the study group may explain the lower prevalence of previous hysterectomy with coital incontinence.

Both urodynamic stress incontinence and detrusor overactivity were the most significant urodynamic findings noted in women reporting coital incontinence. Some studies have shown a strong correlation with coital incontinence and stress incontinence (10). Deep penetration and increased abdominal pressures have been postulated to cause coital incontinence (29). Anatomical studies have not shown any significant findings to explain coital incontinence (4). Some studies have suggested an association of coital incontinence at penetration with stress incontinence and incontinence at orgasm with detrusor overactivity $(3,5)$. Other studies have debated this simple explanation in the etiopathogenesis of CI $(2,4,29)$. Some studies have also shown an association of CI with detrusor overactivity $(3,30)$. Our study showed a significant association of CI with both urodynamic stress incontinence and detrusor overactivity. However, demonstrable $\underline{\mathrm{DOI}}$ had a negative correlation with coital incontinence. A combination of DOI with USI also did not reach statistical significance. This indicates USI (and not DOI) as a significant association with CI. We acknowledge the lack of differentiation between incontinence at penetration or at orgasm in this study. The various risk factors and urodynamic findings associated with coital incontinence indicate a multifactorial etiopathogenesis of coital 
incontinence. It may be difficult to pinpoint the actual "cause" of coital incontinence, as urodynamics was not done during intercourse. Irrespective of the etiopathology, $\mathrm{CI}$ is a bothersome lower urinary tract symptom and should be explored further. It might have an effect on patient expectations and management. Management will however be determined by other bothersome lower urinary tract symptoms. CI might have an impact on outcomes and purposeful enquiry will enable understanding bothersome lower urinary tract symptoms. Follow-up of these patients and to gauge outcomes of any treatment interventions might provide further explanations to understand coital incontinence. Further research is needed to understand the epidemiology, etiopathogenesis and the impact of coital incontinence on women.

\section{Conclusion}

$\mathrm{CI}$ is not uncommon in women with LUTS and they present at a younger age. CI is significantly associated with risk factors like parity, obesity, cigarette smoking and anti-depressant usage. Coital incontinence appears to be multifactorial and is associated with both urodynamic stress incontinence and detrusor overactivity.

\section{Funding: None}

\section{References:}

1. Haylen BT, De Ridder D, Freeman RM, Swift SE, Berghmans B, Lee J, et al. An International Urogynecological Association (IUGA)/International Continence Society (ICS) joint report on the terminology for female pelvic floor dysfunction. Int Urogynecol J. Springer; 2010;21(1):5-26.

2. Jha S, Strelley K, Radley S. Incontinence during intercourse: myths unravelled. Int Urogynecol J. Springer; 2012;23(5):633-7.

3. Serati M, Salvatore S, Uccella S, Nappi RE, Bolis P. Female urinary incontinence during intercourse: a review on an understudied problem for women's sexuality. J Sex Med. Wiley Online Library; 2009;6(1):40-8.

4. El-Azab AS, Yousef HA, Seifeldein GS. Coital incontinence: relation to detrusor overactivity and stress incontinence. Neurourol Urodyn. Wiley Online Library; 2011;30(4):520-4.

5. HILTON P. Urinary incontinence during sexual intercourse: a common, but rarely volunteered, symptom. BJOG An Int J Obstet Gynaecol. Wiley Online Library; 1988;95(4):377-81. 
6. Pons ME, Clota MP. Coital urinary incontinence: impact on quality of life as measured by the King's Health Questionnaire. Int Urogynecol J. Springer; 2008;19(5):621-5.

7. Schäfer W, Abrams P, Liao L, Mattiasson A, Pesce F, Spangberg A, et al. Good urodynamic practices: Uroflowmetry, filling cystometry, and pressure-flow studies**. Neurourol Urodyn. Wiley Online Library; 2002;21(3):261-74.

8. Abrams P, Cardozo L, Fall M, Griffiths D, Rosier P, Ulmsten U, et al. The standardisation of terminology of lower urinary tract function: report from the Standardisation Sub-committee of the International Continence Society. Neurourol Urodyn. Wiley Online Library; 2002;21(2):167-78.

9. Bachmann GA, Leiblum SR, Grill J. Brief sexual inquiry in gynecologic practice. Obstet Gynecol. LWW; 1989;73(3):425-7.

10. A. MORAN SP ZICCONE, P PLD. Urinary leakage during coitus in women. J Obstet Gynecol. Informa UK Ltd UK; 1999;19(3):286-8.

11. Bekker M, Beck J, Putter H, Venema P, Pelger R, Elzevier H. Sexual function improvement following surgery for stress incontinence: the relevance of coital incontinence. J Sex Med. Wiley Online Library; 2009;6(11):3208-13.

12. Tikkinen KAO, Johnson II TM, Tammela TLJ, Sintonen H, Haukka J, Huhtala $\mathrm{H}$, et al. Nocturia frequency, bother, and quality of life: how often is too often? A population-based study in Finland. Eur Urol. Elsevier; 2010;57(3):488-98.

13. Mommsen S, Foldspang A. Body mass index and adult female urinary incontinence. World J Urol. Springer; 1994;12(6):319-22.

14. Noblett KL, Jensen JK, Ostergard DR. The relationship of body mass index to intra-abdominal pressure as measured by multichannel cystometry. Int Urogynecol J. Springer; 1997;8(6):323-6.

15. Foldspang A, Mommsen S, Lam GW, Elving L. Parity as a correlate of adult female urinary incontinence prevalence. J Epidemiol Community Health. BMJ Publishing Group Ltd; 1992;46(6):595-600.

16. Bump RC, McClish DK. Cigarette smoking and urinary incontinence in women. Am J Obstet Gynecol. 1992;167(5):1213-8.

17. Tampakoudis P, Tantanassis T, Grimbizis G, Papaletsos M, Mantalenakis S. Cigarette smoking and urinary incontinence in women-a new calculative method of estimating the exposure to smoke. Eur J Obstet Gynecol Reprod Biol. Elsevier; 1995;63(1):27-30. 
18. Bump RC, McClish DM. Cigarette smoking and pure genuine stress incontinence of urine: a comparison of risk factors and determinants between smokers and nonsmokers. Am J Obstet Gynecol. Elsevier; 1994;170(2):579-82.

19. Broome BAS. The impact of urinary incontinence on self-efficacy and quality of life. Health Qual Life Outcomes. BioMed Central Ltd; 2003;1(1):35.

20. Votolato NA, Stern S, Caputo RM. Serotonergic antidepressants and urinary incontinence. Int Urogynecol J. Springer; 2000;11(6):386-8.

21. Movig KLL, Leufkens HGM, Belitser S V, Lenderink AW, Egberts ACG. Selective serotonin reuptake inhibitor-induced urinary incontinence. Pharmacoepidemiol Drug Saf. Wiley Online Library; 2002;11(4):271-9.

22. Berger M, Gray JA, Roth BL. The expanded biology of serotonin. Annu Rev Med. Annual Reviews; 2009;60:355-66.

23. ZORN BH, MONTGOMERY H, PIEPER K, GRAY M, STEERS WD. Urinary incontinence and depression. J Urol. Elsevier; 1999;162(1):82-4.

24. Hextall A. Oestrogens and lower urinary tract function. Maturitas. Elsevier; 2000;36(2):83-92.

25. Robinson D, Cardozo L. Estrogens and the lower urinary tract. Neurourol Urodyn. Wiley Online Library; 2011;30(5):754-7.

26. Brown JS, Sawaya G, Thom DH, Grady D. Hysterectomy and urinary incontinence: a systematic review. Lancet. Elsevier; 2000;356(9229):5359.

27. Duru C, Jha S, Lashen H. Urodynamic outcomes after hysterectomy for benign conditions: a systematic review and meta-analysis. Obstet Gynecol Surv. LWW; 2012;67(1):45-54.

28. Van Keep PA, Wildemeersch D, Lehert P. Hysterectomy in six European countries. Maturitas. Elsevier; 1983;5(2):69-75.

29. Vierhout ME, Gianotten WL. Mechanisms of urine loss during sexual activity. Eur J Obstet Gynecol Reprod Biol. Elsevier; 1993;52(1):45-7.

30. Khan Z, Bhola A, Starer P. Urinary incontinence during orgasm. Urology. Elsevier; 1988;31(3):279-82. 
